\title{
ANÁLISE DA VIABILIDADE DE UNIVERSITY COWORKING SPACE (UCS) COM BASE NA TEORIA DA INFLUÊNCIA SOCIAL (TIS)
}

\author{
M. B. NÓBREGA ${ }^{1}$, R. L. F. DE ARAÚJO 2 \\ Instituto Federal de Educação, Ciência e Tecnologia do Paraná \\ ORCID ID: http://orcid.org/0000-0003-3331-6426 \\ marianenobrega1@gmail.com ${ }^{1}$
}

Submetido 25/03/2020 - Aceito 16/10/2020

DOI: $10.15628 /$ holos.2020.9776

\section{RESUMO}

O objetivo deste artigo é analisar a viabilidade de implementação de University Coworking Space (UCS) com base na Teoria da Influência Social (TIS) sob a perspectiva discente. Trata-se de uma pesquisa aplicada e exploratória, de natureza qualitativa. A técnica de coleta de dados foi uma entrevista de grupo focal e análise de dados foi feita através de análise do conteúdo, na qual as categorias que representam o material coletado foram obtidas através de perguntas relacionando a implementação de UCS com a TIS, proposta por Kelman (1958), sob a luz do trabalho de Grillo et al. (2014). A TIS se mostrou positivamente relacionada ao UCS, visto que as respostas dos alunos mostraram interesse em participar do modelo, por acreditarem que essa atitude seria vista como positiva por seus professores e colegas ou melhoraria os relacionamentos interpessoais. Conclui-se que o UCS traz benefícios a instituição de ensino e aos alunos que a frequentam, através de ambientes inovativos que promovem a melhoria do processo de formação discente, por permitir a comunicação, socialização e o compartilhamento de conhecimento entre os estudantes e o incentivo a pesquisa, extensão e feedback, tornando sua criação viável e seu funcionamento eficaz, e o apoio efetivo por parte da gestão de cada escola determinante da sua manutenção.

PALAVRAS-CHAVE: University Coworking Space (UCS), Teoria da Influência Social (TIS), Feedback.

\section{ANALYSIS OF THE FEASIBILITY OF UNIVERSITY COWORKING SPACE (UCS) BASED ON THE THEORY OF SOCIAL INFLUENCE (TIS)}

\begin{abstract}
The purpose of this article is to analyze the feasibility of implementing University Coworking Space (UCS) based on Social Theory of Influence (TIS) from the student perspective. It is an applied and exploratory, research of a qualitative nature. The data collection technique was a focus group interview and data analysis was done through content analysis, in which the categories representing the collected material were obtained through questions relating the implementation of UCS with TIS, proposed by Kelman (1958), in light of the work of Grillo et al. (2014). The TIS was positively related to the UCS, since the students' responses showed interest in participating in the model, because they believed that
\end{abstract}

this attitude would be considered positive by their teachers and colleagues or would improve the interpersonal relationships. It is concluded that the UCS brings benefits to the educational institution and the students who attend it, through innovative environments that promote the improvement of the student training process, by allowing communication, socialization and knowledge sharing among students and the incentive research, extension and feedback making its creation feasible and its operation effective, and the effective support by the management of each school that determines its maintenance.

KEYWORDS: University Coworking Space (UCS), Theory of Social Influence (TIS), Feedback. 


\section{INTRODUÇÃO}

Segundo Bussacos (2015), os Coworking Spaces (CWSs) são um modelo de ambiente de trabalho baseado no compartilhamento de espaço e recursos de escritório, podendo reunir pessoas que não trabalhem necessariamente para a mesma empresa ou na mesma área de atuação. Caldeira (1997) e Bauman (1998) indicam uma tendência nas construções físicas recentes em possuírem estruturas fechadas, contribuindo para o isolamento das pessoas. Já os CWSs são espaços físicos nos quais profissionais que trabalham fora do escritório convencional se reúnem, em busca de interação humana (Leforestier, 2009).

No caso dos espaços inseridos em ambientes estudantis, tem-se os University Coworking Spaces (UCSs), modelo complementar à sala de aula tradicional no desenvolvimento discente, com várias características em comum aos CWSs. Os Institutos Federais de Educação, Ciência e Tecnologia (IFs), baseados na tríade ensino, pesquisa e extensão do conhecimento, também podem implementar UCSs, já que muitos estudantes os utilizam como espaço complementar à casa e/ou ao trabalho. Grillo, Nascimento, Damascena e Brasil (2014) afirmam que a motivação do estudante não está relacionada apenas à abordagem de condução das aulas utilizada pelo professor, por mais relevante que ela seja, mas sim atrelada a fenômenos sociais relacionados aos grupos com quem o aluno compartilha as experiências.

Dada a importância dos CWS, deixando-se a desejar estudos sobre UCSs, inclusive relacionados a melhoria nos constructos formulados e analisados com base na TIS, pretende-se responder à questão: Quais fatores relativos ao engajamento e ao feedback dos discentes, com base na Teoria da Influência Social (TIS), podem ser modificados com a participação dos discentes em um University Coworking Space (UCS)? O objetivo deste trabalho é analisar a viabilidade de implementação de University Coworking Space (UCS) com base na Teoria da Influência Social (TIS) sob a perspectiva discente.

Assim, a aplicação de UCSs para IFs pode contribuir para conciliação entre a dinâmica acadêmica/escolar dos estudantes e suas atividades de pesquisa e extensão, permitindo aos estudantes compartilhar conhecimento, discutir de forma interdisciplinar seus projetos e fomentar a criatividade, a cocriação e a colaboração. Dessa forma, este trabalho justifica-se por contribuir para literatura sobre o tema recente, e, na prática, para identificar fatores da Teoria da Influência Social (TIS) que podem ser modificados com a utilização de ambientes distintos dos tradicionais, como os UCSs, e modificar o feedback dos alunos ao processo de aprendizagem e incentivar a criação e disseminação de ambientes inovativos dentro dos espaços acadêmicos e escolares, apoiando a aprendizagem tradicional, além de ser um indicativo, para a instituição, da viabilidade do modelo para a mesma.

Além da Seção 1 - Introdução, este artigo está estruturado em: Seção 2 - Referencial teórico, no qual se abarca a Gestão do Conhecimento: Criatividade e Ambientes Criativos, o University Coworking Space e a Teoria da Influência Social; Seção 3 - Metodologia, na qual se explicita o objeto da pesquisa e a abordagem utilizada; Seção 4 - Resultados e Discussões, que faz referência ao encontrado na análise do grupo focal; Seção 5 - Considerações Finais e, por fim, Seção 6 - Referências utilizadas para embasar a pesquisa. 


\section{REFERENCIAL TEÓRICO}

\subsection{Gestão do Conhecimento: Criatividade e Ambientes Criativos}

De acordo com Dul, Ceylan e Jaspers (2011) compreende-se a criatividade como um processo principalmente coletivo. Bissola e Imperatori (2011) apontam a necessidade de uma maior integração entre as pessoas, buscando-se desenvolver tanto as habilidades criativas individuais, quanto a colaboração, em vistas de produzir um desempenho criativo coletivo. Ambientes repressores, espaços separados e individualizados, intolerância e punições a erros, cumprimento rigoroso das regras, excesso de burocracia, inexistência de espírito de equipe, falta de integração entre os indivíduos, precário sistema de comunicação e medo de ousar, estão entre os principais fatores que podem gerar bloqueios à criatividade (Amabile, Conti, Coon, Lazenby, \& Herron, 1996; Devine, 2006, \& Nicolaci-da-Costa, 2011). Florida e Lopes (2011) afirma que para materializar esse éthos criativo, há necessidade de um ambiente criativo amplo que permeia todas as dimensões da vida humana, como os valores, a sociedade, a cultura do ambiente de trabalho, provocando diversas reflexões sobre o papel do indivíduo, como sua identidade e funções econômica e social.

Botsman e Rogers (2011) defendem três formas, ou sistemas de consumo colaborativo: sistemas de serviços de produtos (em inglês Product-Service System - PSS), mercados de redistribuição e estilos de vida colaborativos. Nos estilos de vida colaborativos se verifica a disposição à partilha e à troca de ativos intangíveis, como, por exemplo, tempo, espaço, habilidades e dinheiro.

A economia compartilhada, também chamada de sharing, compartilhamento, partilha, economia do compartilhamento (sharing economy) ou economia mesh (Gansky, 2010), para Shirky (2012) teve origem na década de 1990, nos Estados Unidos, impulsionada pelos avanços tecnológicos que propiciaram a redução dos custos das transações on-line peer-to-peer. Gansky (2010) afirma que se trata de uma nova tendência que se expande por meio de novas organizações e novos modelos de negócio, com foco no compartilhamento. Segundo Shirky (2012), o conceito de Economias Compartilhadas se propagou pelos EUA na década de 1990, com a grande formação de novas tecnologias, que reduziram os custos de transações online. Constituindo-se de formas comerciais que ajudam ou possibilitam o acesso de bens ou serviços, sem que necessariamente haja a aquisição real de algum produto ou troca monetária (Botsman \& Rogers, 2011).

Para Belk (2007), pode-se compartilhar uma casa de férias, um banco no parque, ou um saco de balas de goma. Inclusive as coisas mais abstratas, como conhecimento, responsabilidade ou poder, bem como ideias, valores e horários, desde que se verifique a disposição à partilha voluntária e à troca de ativos intangíveis, como por exemplo tempo, espaço, habilidades e dinheiro.

$\mathrm{Na}$ economia compartilhada, o consumo é diferente do tradicional, chamado consumo colaborativo (Botsman \& Rogers, 2011) ou consumo conectado (Dubois, Schor, \& Carfagna, 2014), sendo baseado nas pessoas que trabalham de forma colaborativa, compartilham ideias e 
práticas e geram interações, promoções e venda de produtos de forma cooperativa (Botsman \& Rogers, 2011).

A cooperação requer a inserção dos indivíduos nos grupos sociais, a criação de um sentimento de comunidade (Belk, 2007), assim esses comportamentos coletivos destacam a ação coletiva como mais eficaz do que os esforços individuais, promovendo a realização dos objetivos comuns (Barnett, Cloke, Clarke, \& Malpass, 2005).

Para Botsman e Rogers (2011) o consumo colaborativo elimina a necessidade dos intermediários nas transações, permitindo que as trocas diretas entre pares possam ocorrer, sendo baseadas na confiança. Nesse sentido, Briceno e Stagl (2006) destacaram que o sucesso de um sistema cooperativo pode depender, dentre outros fatores, da confiança existente na forma de normas internalizadas e obrigações morais, sugerindo a necessidade de uma adesão arraigada às obrigações e regras.

Para Maurer, Figueiró, Campos, Silva, \& Barcellos (2015) as relações sociais estabelecidas entre os indivíduos participantes do consumo colaborativo podem ser facilitadas pela presença dos laços de confiança, resultando em relações que possam ampliar o compartilhamento de informações, bem como serem influenciadas pelo grau de identificação dos envolvidos.

A economia compartilhada é constituída por práticas que possibilitam o acesso a bens e serviços, sem que haja, necessariamente, a aquisição de um produto ou troca monetária (Botsman \& Rogers, 2011). Dessa forma, a criação de um número cada vez maior de novos modelos de negócio também foi promovida e assim expandiu a economia compartilhada (Gansky, 2010). Este sistema de consumo também pode incluir outras formas de colaboração, como: crowdsourcing, crowdfunding, crowdlearning, couchsurfing e coworking.

\subsection{University Coworking Space}

Beneficiando-se dos valores dos Coworking Spaces (CWSs), no caso de ambientes escolares/acadêmicos, Campos, Teixeira e Schmitz (2015) falam sobre os University Coworking Spaces (UCSs), ambientes híbridos de aprendizagem que possibilitam o desenvolvimento de trabalhos acadêmicos, pesquisas, atividades regulares de empresas juniores, desenvolvimento de projetos, novos negócios (startups e spinoffs universitárias), bem como servem de espaço de trabalho para estudantes que já possuem negócios ou empresas que possuem relacionamento de negócios com a universidade e instalam unidades da sua empresa nos UCSs. Nesses ambientes ocorre uma aprendizagem informal, típica desses modelos, que ocorre pela experiência e no relacionamento peer-to-peer (Mendes \& Duarte, 2015).

De acordo com Bautista e Borges (2013), para a transformação dos ambientes de aprendizagem tradicionais em "smart classroom" (modelos de aprendizagem distintos dos ambientes tradicionais), pode-se valer de direcionadores, como: (a) design físico flexível; (b) adaptabilidade as necessidades de professores e estudantes; (c) conforto para o desenvolvimento de diversos tipos de atividades didáticas; (d) espaço propício para a multiplicidade de estímulos; (e) conectividade potencializando o uso de smartphones, tablets, 
notebooks, smartwatches, entre outros dispositivos móveis; (f) personalização; (g) organização e orientação do ambiente conforme o tipo de atividade a ser desenvolvida; (h) abertura para a interação com ambientes presenciais e virtuais além do espaço físico da sala de aula, bem como, da participação de ativos do conhecimento externos; (i) segurança e ergonomia, segurança de dados e acesso à internet.

Com base em Campos, Teixeira e Schmitz (2015), diversos tipos de atividades podem ser ofertadas, como: ações de formação e capacitação (palestras; workshops; cursos; visitas técnicas; seminários; fóruns; aulas presenciais e virtuais; web conferências); ações de geração de networking (encontros, almoços, jantares, brunches, cafés, reuniões, missões empresariais; rodadas de negócios e outras manifestações que aproximem pessoas e potencialidades); e, ações de inovação e empreendedorismo (startup weekends e derivados; boot camps; pitch de apresentações; semana global de empreendedorismo; hackthons, encontros com mentores; feiras de inovação e empreendedorismo; projetos em coworking spaces, fab labs, makerspaces, pesquisa e desenvolvimento, prototipagem, entre outras); captação de subsídios e fomentos públicos e privados, vendas de serviços (aluguel de sala de reunião, organização de seminários, cafetaria) e patrocínio por empresas de maior dimensão.

Todavia, a implementação de qualquer projeto necessita inicialmente da exposição dos seus objetivos para os envolvidos. Para que seja implementado um UCS, os gestores devem ter claro quais os comportamentos básicos (in-role) e quais os comportamentos discricionários (extra-role) esperados em relação ao desempenho dos alunos. Nesse caso, tem-se o frame proposto pela Teoria da Influência Social (TIS), que vai muito além de realizar as tarefas propostas pelo professor em sala de aula e desenvolver atividades de pesquisa e extensão - que poderiam, no contexto dos IFs, serem consideradas desempenho contextual, por não serem obrigatórias para os alunos.

\subsection{Teoria da Influência Social}

Para analisar como um UCS pode contribuir para melhoria do desempenho dos estudantes, este estudo tem como base o trabalho de Grillo et al. (2014), que utilizou a Teoria da Influência Social (TIS), proposta por Kelman (1958), no qual indica três modos de influência social: (1) complacência; (2) identificação; e (3) internalização. Grillo et al. (2014) buscaram analisar antecedentes do comportamento proativo de fornecimento de feedback do aluno ao professor com vistas à cocriação de valor. Inicialmente são analisados os antecedentes do comportamento discricionário do estudante, através do feedback apresentado, avaliado com base no constructo engajamento, proposto por Vivek, Beatty e Morgan (2012). Segundo Payne, Storbacka e Frow (2008), poucas pesquisas analisam os motivadores desse constructo no comportamento do indivíduo.

A Teoria da Influência Social (TIS) está relacionada com a explicação dos processos sociais que causam mutações nas ações dos indivíduos. De acordo com Kelman (1958), existem três tipos de influência social: (1) complacência; (2) identificação; e (3) internalização, sendo seus respectivos constructos estabelecidos por Bagozzi e Lee (2002): norma subjetiva, identidade social e norma de grupo. A complacência (norma subjetiva), segundo Kelman (1958), é o efeito 
da crença do indivíduo de que a adoção de determinado comportamento trará reações positivas do grupo ou de alguém relevante para ele. A identificação (identidade social), refere-se à adoção de atitudes pelo indivíduo com o objetivo de reforçar sua identificação com o grupo ou sua autoidentidade, nas esferas cognitivas, afetiva e avaliativa do sentimento de pertencimento gregário, e não apenas os benefícios diretos daquele comportamento (Kelman, 1958). Já a internalização (norma de grupo) é quando o indivíduo adota comportamentos existentes em um grupo em função do mesmo ser coerente com seu próprio sistema de valores (Kelman, 1958).

Assim, a TIS explica processos de natureza social capazes de influenciar atitudes e comportamentos do indivíduo (Grillo et al., 2014). Grillo et al. (2014) testam os efeitos de processos de influência social e seus constructos como antecedentes diretos do engajamento, proposto por Vivek, Beatty e Morgan (2012), e este como antecedente direto do feedback do aluno, que pode mostrar ou não uma cocriação de valor no ambiente de estudo.

Relacionado a conceitos nas mais diversas áreas, o feedback se trata da resposta do sujeito a determinada ação/situação. Assim como o feedback, o termo "engajamento" é utilizado por diversas áreas. Para Vivek, Beatty e Morgan (2012), refere-se a níveis elevados de intensidade na forma como o indivíduo se envolve em determinadas atividades e com determinados objetos. Vivek (2009) afirma que o engajamento é um constructo formado pelas dimensões: entusiasmo, participação consciente e interação social.

O entusiasmo está relacionado a realizações vinculadas ao objeto focal de determinado indivíduo, a participação consciente está associada a atenção que o indivíduo dá aquela atividade, podendo ocorrer também inconscientemente, e a interação social do indivíduo engajado relaciona-se ao seu envolvimento dinâmico e intenso em oportunidades de relacionamento com outros indivíduos que também interagem com o objeto focal (Vivek, 2009).

\section{METODOLOGIA}

Seguindo a definição de Marconi e Lakatos (2017), no que se refere a caracterização da pesquisa, quanto a natureza, trata-se de uma pesquisa aplicada, de natureza qualitativa, quanto ao objetivo, é uma pesquisa exploratória, quanto aos procedimentos, é uma pesquisa de levantamento de dados, relacionada a um estudo de caso no Instituto Federal do Amapá (IFAP), Campus Santana. A técnica de coleta e análise de dados foi uma entrevista de grupo focal com perguntas relacionando a implementação de University Coworking Space (UCS) com a Teoria da Influência Social (TIS), proposta por Kelman (1958), sob a luz do trabalho de Grillo et al. (2014).

O grupo focal é uma discussão em grupo em que o pesquisador esteja ativamente atento e encorajando às interações do grupo (Barbour \& Kitzinger, 1999). A técnica utilizada na coleta de dados foi uma entrevista de grupo focal, que é uma técnica muito útil quando se está interessado em compreender as diferenças existentes em perspectivas, ideias, sentimentos, representações, valores e comportamentos de grupos diferenciados de pessoas, bem como compreender os fatores que os influenciam, as motivações que subsidiam as opções, os porquês de determinados posicionamentos (Gatti, 2005). Gatti (2005) argumenta que na análise das discussões do grupo focal, a elaboração e a busca do significado dos argumentos estão vinculadas ao pesquisador e seu estofo teórico e criatividade. Assim, a análise de dados foi feita através de análise do 
conteúdo, na qual as categorias que representam o material coletado foram obtidas através de perguntas relacionando a implementação de UCS com a TIS, proposta por Kelman (1958), sob a luz do trabalho de Grillo et al. (2014).

Nesta pesquisa, o grupo focal englobou alunos do 1 e e 2 을 ano do ensino médio do IFAP, Campus Santana, dos cursos técnico em Publicidade, Comércio, Marketing e Logística. Antes do início dos encontros o tema foi explicado aos participantes que ainda não tinham conhecimento prévio sobre UCS. Os encontros do grupo ocorreram em dois dias, com a duração de 1 hora e 30 minutos no primeiro encontro e 2 horas e 5 minutos no segundo encontro, com a participação de 9 alunos no primeiro e 9 no segundo dia. O número de participantes do grupo focal vai de encontro com Gondim (2002), em que o grupo precisa de 4 a 10 participantes, para que o desempenho e participação de cada pessoa não seja prejudicado e que torne a moderação mais fácil. Para facilitar o processo de análise e para que nenhuma informação fosse perdida, todas as falas do grupo focal foram gravadas e em seguida foram transcritas. Além disso, todos os participantes foram esclarecidos e assinaram o Termo de Consentimento Livre e Esclarecido (TCLE).

\section{RESULTADOS E DISCUSSÕES}

\subsection{Comportamento Discricionário}

O comportamento dito discricionário envolve ações que vão além das funções básicas do indivíduo e, nesse contexto, tem implicações positivas para seus agentes de interação (Grillo et al., 2014). Desse modo, ao ser implantado um UCS em um ambiente escolar/acadêmico, inclusive um IF, deve-se estabelecer quais constructos serão objetivo de melhoria, ou seja, em quais aspectos do estudante pretende-se intervir para cocriação de valor com o conteúdo/abordagem do professor em sala de ação, através da melhoria do feedback do aluno nas disciplinas.

No caso desta pesquisa, os resultados indicam que, ao se implementar um UCS, tem-se em mente um local em que os alunos podem sentirem-se à vontade para estudar assuntos direcionados pelo professor em sala de aula (comportamento in-role) ou assuntos correlatos, instigados através de questionamentos surgidos por debates com os colegas (comportamento extra-role). Ao mesmo tempo, alunos e professores podem utilizar o UCS para desenvolver atividades de extensão, em projetos que já participem (in-role) ou que desejem desenvolver e participar (extra-role), seja de cunho cultural, tecnológico, social, etc. Alunos e professores podem, ainda, utilizar o UCS no desenvolvimento de atividades de pesquisa, inclusive sendo membros de grupos de pesquisa ou estando inseridos em projetos de pesquisa (in-role) ou pelo simples desejo de pesquisar determinado tema de interesse (extra-role). Essas e outras ações são vistas como manifestações de cocriação de valor no ambiente de estudo.

Foi destacado pelos participantes do grupo focal o fato de que esse modelo se diferencia dos modelos convencionais de compartilhamento presentes nas instituições de ensino por ter uma característica informal (por exemplo, a gestão é feita pelos próprios usuários - semelhante a um centro acadêmico em uma universidade) e permitirem um relacionamento peer-to-peer, que exige interação e confiança entre os pares (independentemente da forma como a mesma é 
adquirida, como, por exemplo, através do relacionamento cotidiano em sala de aula ou por gostos comuns, extra sala de aula).

\subsection{Feedback}

Segundo Ashford e Cummings (1983), na medida em que o desempenho e os objetivos pessoais são importantes para o indivíduo, o feedback sobre o seu comportamento e sobre o ambiente em que estão inseridos se torna um recurso informativo valioso, portanto, a mudança de perspectiva sobre o feedback faz com que os indivíduos mudem sua postura quanto ao tema, mostrando a importância do processo. Desse modo, inicialmente, deixou-se claro que no caso da instituição de ensino o feedback pode ocorrer tanto em relação a sala de aula, como a todos os outros aspectos institucionais, sendo esses o foco da melhoria pretendida com o UCS em relação ao feedback dos estudantes.

Nesse caso, com base nos resultados, pode-se dizer que para implantação do UCS deve-se prever mecanismos de feedback, que podem ser informais, decorrentes da interação entre os próprios indivíduos, afinidades, aproximações, entre outros, ou mecanismos formais, propiciados pela instituição de ensino até mesmo para justificar a existência do modelo, como instrumentos de verificação da melhoria do desempenho dos alunos em sala de aula. Isso porque é evidente que se espera que a inserção dos alunos em um UCS melhore seu desempenho geral, ou seja, não apenas sua avaliação tradicional, como as notas do aluno, mas também sua resposta ao estímulo social, como a interação com o grupo e a melhoria de questões psicossociais. Por isso, percebeu-se como importante e até mesmo decisiva a escolha do instrumento adequado de aferição do feedback antes e depois da implantação do UCS.

As perguntas relacionadas ao feedback têm como objetivo analisar o retorno das informações entre os alunos, professores e setores da instituição, verificando também se há local e momento para que esse feedback ocorra.

$\mathrm{Na}$ maioria das respostas dos discentes em relação ao feedback, apresentam-se argumentos da existência de ouvintes para o feedback em sala de aula, mas não de forma abrangente, pois não sentem que as opiniões dadas realmente mudarão algum aspecto que os desagrada em sala de aula ou aspectos gerais da instituição. Os alunos indicaram em suas respostas a necessidade de maior integração com a instituição a respeito de suas opiniões (o feedback), pois se sentem muitas vezes inseguros em repassá-las. As respostas mostram ser difícil a adaptação para a avaliação tradicional da instituição.

Além disso, a maioria dos alunos afirma ter boa relação apenas com parte de um grupo, não se conseguindo ou evitando ter uma relação com outros grupos pelos meios já existentes para isso (ambientes já presentes no instituto). O grupo afirmou concordar que na interação mais informal oferecida por um UCS melhoraria o desempenho, já que o contato com outros alunos de outras turmas do instituto proporcionaria a troca de informações e contribuiria para melhorar as questões de feedback, facilitando a busca por resoluções de problemas institucionais de maneira mais rápida, organizada e eficiente. 


\subsection{Engajamento}

Vê-se o engajamento como proeminente em contribuir para um comportamento de proatividade por parte do aluno, na busca por uma alteração no status quo do ambiente de aprendizagem, através de atitudes inovativas que decorrem um uma cocriação de valor nesse ambiente. Portanto, o engajamento pode ser visto como uma forma de se obter comportamentos de cocriação de valor buscados em um UCS.

Analisando o processo de influência social caracterizado como engajamento e os estímulos contextuais incentivados pelo UCS que levam o indivíduo a se engajar, a maior parte das respostas mostra que os alunos, em sua maioria, se sentem entusiasmado em desempenhar suas atividades na infraestrutura oferecida pela instituição, porém apontam que não têm plena consciência e participação nas atividades acadêmicas, sendo feito apenas o que é básico para contribuir em suas médias finais. Parte do grupo afirmou não ter muitos relacionamentos informais além do seu grupo efetivo de amigos, e uma pequena parte indicou ter relacionamentos informais com outros alunos e servidores do instituto.

Os alunos afirmaram que teriam orgulho e se sentiriam confortáveis em um ambiente espaço planejado e criado por eles, trazendo mais entusiasmo na execução das suas atividade, juntamente com mais liberdade que o UCS possibilita, tendo um momento para estudos e um momento para a descontração, assim como permitiria o amadurecimento enquanto grupo, já que o funcionamento e problemas do UCS seriam geridos pelos alunos.

Segundo os alunos, eles participariam mais ativamente em um UCS, pois a monotonia da sala de aula não cria alunos entusiasmados, além de que os alunos que não prestam atenção e interrompem as aulas também são fatores que desmotivam os alunos, enquanto que no UCS, com seus diversos espaços, eles podem trocar informações com diversos alunos de outras turmas que estão ali por vontade própria para estudar.

\subsection{Teoria da Influência Social}

Grillo et al. (2014) explicam que nas relações colaborativas de consumo, no caso na instituição de ensino, em seus três modos, a influência social possui efeitos positivos sobre comportamentos participativos do indivíduo. Assim, com base no contexto analisado neste artigo, entende-se que diversos comportamentos possibilitados pela criação de um UCS podem gerar esses efeitos positivos, encaixando-se nos três modos de influência social da TIS.

Grillo et al. (2014) interpretam a complacência (norma subjetiva) como a expectativa que o indivíduo possui de respostas a seus comportamentos, podendo-se considerar, por exemplo, que parte do engajamento do estudante é efeito de sua expectativa de reações de familiares, amigos e até mesmo do professor, podendo o engajamento ser resultado de um processo mental deliberativo, estimulado pela complacência. Esse constructo da Teoria da Influência Social se refere a adaptação do indivíduo para relacionar-se a seu grupo. Foram feitas duas perguntas quanto ao constructo complacência, para avaliar a visão dos alunos sobre seus atos e comportamento, sendo obtidas oito respostas. Assim, tem-se como resultado que a norma subjetiva, no contexto do UCS pode ser vista como o consumo colaborativo proporcionado pelo modelo em questão e que pode ser caracterizada, sobretudo, na relação peer-to-peer 
(mencionada anteriormente). Outras fontes de complacência no modelo de UCS podem ser a ideia de ambiente inovativo e a expectativa de resposta da organização aos investimentos físicos no UCS. Nesse sentido, percebe-se como principal diferença entre o CWS e o UCS a necessidade de investimento - e não intervenção - da instituição no que se chamou de estímulos contextuais físicos que levam o indivíduo ao engajamento.

No grupo focal, os alunos em parte reconheceram adotar determinados comportamentos em função da perspectiva dos outros (como ele será visto), e uma pequena parte, mais fechada, acredita que não faz parte do seu perfil esse comportamento. O grupo identificou que participar desse ambiente é visto de forma positiva para outros discentes e demais pessoas do instituto. Tornou-se evidente que os alunos adotam determinadas ações em função delas serem vistas como positivas.

No processo de identificação (identidade social), a influência social que se dá por meio da identificação que leva o indivíduo a buscar a autoidentidade na forma de reconhecimento dele pelos integrantes do grupo (Grillo et al., 2014). Para Grillo et al. (2014), a identidade social tem efeito positivo em esforços discricionários para o indivíduo se destacar e reforça a autoestima individual e coletiva. Quanto ao constructo identificação, foram feitas duas perguntas para analisar a avaliação da autoidentidade dos alunos e sua relação com o grupo, sendo obtidas sete respostas. No contexto do UCS, destacou-se a potencial identidade local desenvolvida, sobretudo com o amadurecimento do modelo, que pode fazer com que os participantes promovam comportamentos discricionários por diversos motivos, como reforço das imagens individuais e coletivas perante o grupo frequentador do UCS e a instituição de ensino como um todo e, até mesmo, a comprovação de que "vale a pena" manter e investir no modelo por parte dos gestores. Assim como em Grillo et al. (2014), entende-se que a identidade social pode gerar efeito positivo sobre o engajamento dos estudantes, ou seja, o modelo pode proporcionar uma melhora no desempenho geral dos estudantes na instituição de ensino.

Nesse constructo da identidade social, em que o indivíduo reforça sua identidade para ser valorizado no grupo, entre os participantes do grupo focal a maior parte dos alunos afirmou que mudou de comportamento, seus hábitos e atitudes, ao ingressar na instituição para se adequar aos valores da mesma, e apenas uma minoria afirmou não ter ocorrido mudanças em seus perfis não precisaram mudar sua autoidentidade, pois já identificavam com o ambiente.

O último constructo da TIS, a internalização (norma de grupo), indica que o indivíduo se envolve em atividades do grupo em uma intensidade proporcional a sua percepção do nível em que os comportamentos existentes no grupo são coerentes com seu próprio sistema de valores, ou seja, quanto mais o indivíduo internalizar os comportamentos do grupo, mais engajado ele estará nas atividades - se refere aos objetivos e valores em comuns do indivíduo com o grupo, abordando também a relação do grupo com a UCS. Grillo et al. (2014) explicitam uma série de objetivos que podem ser percebidos como comuns aos membros do grupo, como: obter êxito na realização de um trabalho; obter resultados favoráveis nas avaliações dos professores; ou mesmo elevar o domínio de conhecimento em uma disciplina. Nesse caso, entendeu-se o UCS como um local que pode possibilitar o encontro de estudantes com interesses em comum, que não necessariamente se restrinjam a atividades de ensino. 
Sobre a internalização, foram feitas oito perguntas para analisar a relação do grupo com o UCS e com o IFAP, assim como a identificação dos valores e objetivos dos mesmos, com um total de 21 respostas. Todos do grupo afirmaram que desconhecem alguns valores da instituição, porém compactuam com a maioria dos valores que conhecem por acharem corretos. Os alunos afirmam que em seus grupos de sala de aula os valores divergem, mas que sempre buscam ouvir todas as diferentes opiniões, para entrar em consenso, e apontam que poucos objetivos em comum são encontrados em seus grupos, principalmente nas questões das atividades de classe e extraclasse. Todos os participantes se identificaram com os valores do modelo de UCS apresentado e afirmaram que o modelo se adequa aos valores do IFAP, porém, na medida em que é usado para outros fins, pode ferir estes valores.

Para garantir que seja utilizado dentro de seus objetivos, sugeriram que organizações como o grêmio estudantil da instituição poderia coordenar o local, e que haja uma sensibilização de que os estudantes podem participar do UCS por vontade própria, portanto, ao ingressar nesse ambiente, devem estar cientes das regras do UCS e ter objetivos em comum aos propostos. Destacou-se que o UCS pode ir além das questões institucionais, funcionando como um ambiente de cooperação, em que ocorre a troca de informações, como aprender novos hobbies, interesse em comum por filmes, músicas, livros, etc. De acordo com os alunos, o UCS pode proporcionar novos relacionamentos com pessoas que possuem um objetivo comum, como gosto musical, vestibular, trocar conhecimentos, etc.

\subsection{University Coworking Space}

Quanto a forma de criação e funcionamento do UCS, foram feitas três perguntas referentes a visão dos alunos, e obtidas nove respostas. Entre as respostas, destacou-se que o UCS precisa de materiais para garantir o bem-estar dos alunos, seja para o conforto, com mesas, cadeiras, como também para tornar o ambiente mais dinâmico, com computadores, projetores, quadros, etc. Além de recursos materiais, é necessário apoio dos professores e servidores da instituição para que o UCS seja mais efetivo e que fortaleçam o ambiente, tornando as decisões tomadas pelos membros do local válidas dentro da instituição, seja um pedido de material ou feedback por parte dos alunos, e que os mesmos participem do processo de feedback em conjunto com os alunos.

Para garantir a continuidade e a efetividade do UCS, a avaliação de desempenho contínua é essencial para que os alunos continuem frequentando o ambiente. O UCS precisa de feedback constante para que seja utilizado como medida de produtividade e eficácia do ambiente, que pode ocorrer por meio de questionários semanais, assim podendo corrigir e melhorar o ambiente para que seja mais produtivo aos seus participantes. Reuniões de incentivo a pesquisa e momentos de descontração podem atuar como formas de incentivo para os alunos que utilizam o UCS. Além disso, o ambiente precisa funcionar de forma interativa para que incentive seus participantes a pesquisa e a extensão, até mesmo melhorar o desempenho das avaliações tradicionais, melhorando o entusiasmo e a motivação dos alunos.

Após o término das perguntas temática, foram feitas duas perguntas de verificação para validar as questões e relembrar as questões discutidas, assim como rever algum assunto 
pendente da temática, que mostraram que, para o grupo focal, os assuntos mais pertinentes relacionados ao UCS foram o comprometimento e a responsabilidade do aluno para com esse ambiente, visto que nele seus integrantes precisam fazer manutenção e gerir o espaço.

\section{CONSIDERAÇÕES FINAIS}

A implementação do UCS visa o comportamento discricionário, relacionado ao que vai além das atividades básicas do aluno, trazendo benefícios através de uma nova perspectiva do que foi abordado em sala pelas ações básicas, propondo que aja um "algo a mais" em relação ao que é efetivamente cobrado do discente, o que se caracteriza como criação de valor, não apenas na sala de aula, mas em todo ambiente escolar.

O primeiro benefício da criação do UCS apontado é o engajamento dos alunos em atividades institucionais, indicando resultados positivos no comportamento desses alunos com melhoria na participação deles em atividades dentro e fora de sala de aula, em atividades de regulares ou extraclasse. O feedback também seria melhorado com a implementação do modelo, pois existe a necessidade de interação com outros indivíduos e a criação de um ambiente informal, onde o aluno possa interagir e expressar individual ou coletivamente o feedback à instituição. Os alunos não se sentem à vontade para dar individualmente feedback à instituição por não haver oportunidade ou por receio.

A TIS se mostrou positivamente relacionada ao UCS, visto que as respostas dos alunos mostraram interesse em participar do modelo, por acreditarem que essa atitude seria vista como positiva por seus professores e colegas ou melhoraria os relacionamentos interpessoais. Os principais fatores da TIS influenciados pelo UCS foram: expectativa das suas ações, como também da maneira que as ações serão vistas por familiares/amigos, a adaptação do aluno a seu grupo ou conhecer novos grupos no UCS (complacência), reforçar a autoidentidade e mudar seus hábitos e costumes para adequar-se adaptar-se ao grupo ou ao instituto (identidade), por fim, seria um modelo viável de UCS na medida em que os alunos se identificam com os valores do modelo e acreditam que possui os mesmos valores do IFAP e os alunos se sentem mais à vontade para expressar suas opiniões de maneira informal e pela percepção de que não seriam prejudicados por isso, na maneira como o indivíduo se envolve com as atividades do grupo, que pode influenciar o UCS através da criação de seus próprios valores (internalização). Percebe-se que os alunos compartilham dos mesmos valores que o IFAP, enquanto que seus valores divergem com o grupo a qual se relaciona.

Quanto ao seu funcionamento, o modelo de UCS seria completamente gerenciado pelos alunos, com a ajuda dos servidores para criar um ambiente agradável, que possua avaliação contínua para manter os alunos frequentando o local e os mantendo produtivos e engajados.

Conclui-se que o UCS traz benefícios a instituição de ensino e aos alunos que a frequentam, através de ambientes inovativos que promovem a melhoria do processo de formação discente, por permitir a comunicação, socialização e o compartilhamento de conhecimento entre os estudantes e o incentivo a pesquisa, extensão e feedback, tornando sua criação viável e seu funcionamento eficaz, e o apoio efetivo por parte da gestão de cada escola determinante da sua manutenção. 


\section{REFERÊNCIAS}

Amabile, T. M., Conti, R., Coon, H., Lazenby, J., \& Herron, M. (1996). Assessing the work environment for creativity. Academy of management journal, 39(5), 1154-1184.

Ashford, S. J., \& Cummings, L. L. (1983). Feedback as an individual resource: Personal strategies of creating information. Organizational behavior and human performance, 32(3), 370-398.

Bagozzi, R. P., \& Lee, K. H. (2002). Multiple routes for social influence: The role of compliance, internalization, and social identity. Social psychology quarterly, 226-247.

Barbour, R., \& Kitzinger, J. (Eds.). (1999). Developing focus group research: politics, theory and practice. Sage.

Barnett, C., Cloke, P., Clarke, N., \& Malpass, A. (2005). Consuming ethics: Articulating the subjects and spaces of ethical consumption. Antipode, 37(1), 23-45.

Bauman, Z. (1998). O mal-estar da pós-modernidade. Rio de Janeiro: Jorge Zahar, 121-130.

Bautista, G., \& Borges, F. (2013). Smart classrooms: Innovation in formal learning spaces to transform learning experiences. Bulletin of the IEEE technical Committee on learning Technology, 15(3), 18-21.

Belk, R. (2007). Why not share rather than own? The Annals of the American Academy of Political and Social Science, 611(1), 126-140.

Bissola, R., \& Imperatori, B. (2011). Organizing individual and collective creativity: Flying in the face of creativity clichés. Creativity and Innovation Management, 20(2), 77-89.

Botsman, R., \& Rogers, R. (2011). O que é meu é seu: como o consumo colaborativo vai mudar o nosso mundo. Bookman Editora.

Briceno, T., \& Stagl, S. (2006). The role of social processes for sustainable consumption. Journal of Cleaner Production, 14(17), 1541-1551.

Bussacos, H. (2015). Codesign Impact Hub Floripa. São Paulo: Impact Hub.

Caldeira, T. P. R. (1997) Enclaves Fortificados: a Nova Segregação Urbana. Estudos CEBRAP, 47, 155-176.

Campos, J. G. C., Teixeira, C. S., \& Schmitz, A. (2015). Coworking spaces: Conceitos, tipologias e características. In Conference Paper presented at Congresso Internacional de Conhecimento e Inovação, Joinville, SC, Brazil (Vol. 5).

Devine, M. (2006). Creativity in the World of Work. Peer Review, 8(2), 8.

Dubois, E., Schor, J., \& Carfagna, L. (2014). Connected consumption: a sharing economy takes hold. Rotman Management, 1, 50-55. 
Dul, J., Ceylan, C., \& Jaspers, F. (2011). Knowledge workers' creativity and the role of the physical work environment. Human resource management, 50(6), 715-734.

Florida, R. L., \& Lopes, A. L. (2011). A ascensão da classe criativa. Porto Alegre, RS: L\&PM.

Gansky, L. (2010). The mesh: Why the future of business is sharing. Penguin.

Gatti, B. A. (2005). Grupo focal na pesquisa em ciências sociais e humanas. In Grupo focal na pesquisa em ciências sociais e humanas, 77-77.

Gondim, S. M. G. (2002). Grupos focais como técnica de investigação qualitativa: desafios metodológicos. Paidéia (Ribeirão Preto), 12(24), 149-161.

Grillo, T. L. H., Nascimento, T. M., Damacena, C., \& Brasil, V. S. (2014). Cocriação de valor com alunos: uma análise da influência social e do engajamento na disciplina como antecedentes de feedback do estudante. Administração: Ensino e Pesquisa, 15(3), 533-559.

Kelman, H. C. (1958). Compliance, identification, and internalization three processes of attitude change. Journal of conflict resolution, 2(1), 51-60.

Leforestier, A. (2009). The coworking space concept. CINE Term Project. Indian Institute of Management (IIMAHD). Ahmedadad, n. February, 1-19.

Marconi, M. A., \& Lakatos, E. M. (2017). Fundamentos de Metodologia Científica (8 ed.). São Paulo: Atlas.

Maurer, A. M., Figueiró, P. S., Campos, S. A. P., Silva, V. S., \& Barcellos, M. D. (2015). Yes, we also can! O desenvolvimento de iniciativas de consumo colaborativo no Brasil. BASE: revista de administração e contabilidade da Unisinos. BASE: UNISINOS accounting and administration journal. São Leopoldo, RS. Vol. 12, n. 1 (jan./mar. 2015), p. 68-80.

Mendes, F., \& Duarte, C. (2015). Coworking as a stigmergic and informal learning space. In 8th International Conference Senses and Sensibility, Lisbon.

Nicolaci-da-Costa, A. M. (2011). O talento jovem, a internet e o mercado de trabalho da "economia criativa". Psicologia \& Sociedade, 23(3), 554-563.

Payne, A. F., Storbacka, K., \& Frow, P. (2008). Managing the co-creation of value. Journal of the academy of marketing science, 36(1), 83-96.

Shirky, C. L. A. Y. (2012). Lá vem todo mundo: o poder de organizar sem organizações. Editora Schwarcz-Companhia das Letras.

Vivek, S. D. (2009). A scale of consumer engagement (Doctoral dissertation). The University of Alabama.

Vivek, S. D., Beatty, S. E., \& Morgan, R. M. (2012). Customer engagement: Exploring customer relationships beyond purchase. Journal of marketing theory and practice, 20(2), 122-146. 


\section{COMO CITAR ESTE ARTIGO:}

Nóbrega, M. B., Araújo, R. L. F. de (2020). Análise da viabilidade de University Coworking Space (UCS) com base na Teoria da Influência Social (TIS). Holos. 36(6), 1-15.

\section{SOBRE OS AUTORES}

\section{B. NÓBREGA}

Possui graduação em Administração de Empresas pela Universidade Federal de Campina Grande (2011), mestrado em Administração pela Universidade Federal da Paraíba (2014) e especialização em Docência na Educação Profissional e Tecnológica pelo Instituto Federal de Educação, Ciência e Tecnologia do Amapá (2018).

E-mail: marianenobrega1@gmail.com

ORCID ID: http://orcid.org/0000-0003-3331-6426

\section{R. L. F. DE ARAÚJO}

Graduado em Ciências Contábeis pelo Centro Universitário de João Pessoa - Unipê. Mestre em Administração com ênfase em Finanças pela Universidade Federal da Paraíba - UFPB. MBA na linha de Finanças, Controladoria e Auditoria pela Fundação Getúlio Vargas - FGV. Atualmente é professor EBTT do Instituto Federal do Paraná - IFPR.

E-mail: rodrigo.farias@ifpr.edu.br ORCID ID: https://orcid.org/0000-0002-7497-6212

Editor(a) Responsável: Francinaide de Lima Silva Nascimento Pareceristas Ad Hoc: Anderson Costa e Sheldon Silva

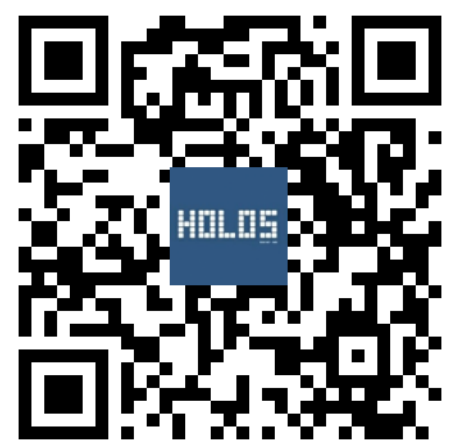

